\title{
Educação Permanente: a Saída para o Trabalhador na Era da Qualidade Total*
}

\author{
Ana Shirley de França Moraes \\ Universidade Estácio de Sá (Unesa)
}

Apresenta o tema da educação permanente, a partir da investigação realizada para a pesquisa $\mathrm{O}$ trabalhador-estudante no ensino superior: suas representações e expectativas em relação ao mercado de trabalho e ao ensino, para fundamentar a busca pelo saber escolarizado por parte do trabalhador, que muitas vezes se vê sacrificado e a sua família, mas se mantém determinado a realizar os estudos, concomitantemente ao trabalho. Faz uma retrospectiva teórica sobre o tema, analisando estudos de intelectuais brasileiros e seus enfoques. A seguir, aborda o tema da qualidade total, em breve caracterização, mostrando sua relação com a educação do ponto de vista marxista, pedagógico e epistemológico, revelando, assim, a presença do "aprender a aprender", fundamento básico da educação permanente implícito nos pressupostos da qualidade total.

\section{Introdução}

Faz parte da essência do homem a necessidade e o desejo de buscar mais e mais conhecimento. O saber adquirido ao longo da vida, quer de natureza informal, recebido no meio e na família; ou formal,

*A pesquisa $O$ Trabalhador Estudante no Ensino Superior: suas Representações e Expectativas em Relação ao Mercado de Trabalho e ao Ensino, que deu origem a este trabalho, constitui uma das linhas de pesquisa do mestrado em Educação, da Universidade Estácio de Sá (Unesa), no Rio de Janeiro. O grupo responsável pela pesquisa é composto pelas professoras Ana Shirley de França Moraes (coordenadora) e Lúcia Helena Martins Gouvêa, pelo professor Renato Ferreira Carr e por alguns alunos de graduação. 
fruto da educação escolarizada, não se esgota. Quanto mais se vive mais se aprende ou se quer aprender. Por esta razão, o tema da educação permanente vem permeando, ao longo dos anos, as discussões educacionais baseadas nos valores ontológicos do homem.

Várias abordagens do tema foram feitas, ora de cunho filosófico, ora pedagógico ou econômico, entre outros, mas fundamentalmente vinculando a educação ao processo capitalista monopolista de desenvolvimento, implantado no Brasil a partir da década de 60 .

Atualmente, em função do momento "qualidade total", nota-se subjacente aos seus preceitos o fundamento básico da educação permanente, ou seja, a disposição do "aprender a aprender". A apresentação desse vínculo torna-se objeto deste trabalho.

O modelo econômico adotado a partir de 1964, período militar de governo, um marco em termos de trajetória político-econômica, trouxe a definitiva inserção da economia brasileira ao controle do capital internacional. Tal modelo pregava a modernização, assegurando a expansão de mercados, porém aumentando a distância em todos os níveis, entre os centros criadores de tecnologia e ciências e os países consumidores, como era o caso brasileiro. Este processo imperialista, marcado pela ação do capital estrangeiro, em sua lógica de acumulação e centralização, conduziu à intervenção das "metrópoles" não só no plano econômico, mas, da mesma forma, nos planos político, social e educacional. E claro que, para suprir as exigências do novo mercado que se criara, o sistema de ensino deveria adaptar-se, reformar-se, à luz das novas exigências de qualificação profissional, a fim de se adequar às novas perspectivas ocupacionais, em função da crescente oferta de trabalho criada (Romanelli, 1989).

Neste clima, vêm à cena estudos da Unesco produzidos por intelectuais estrangeiros, cujo principal escopo era ver a educação sob a ótica econômica, dando destaque à expressão educação permanente. No Brasil, como era de se esperar, o conceito constituiu-se modismo educacional, nas décadas de 60 a 70 , e a ele se dedicaram vários estudiosos da educação, com diferentes definições e enfoques. 
contudo, antes de abordar as concepções dos intelectuais brasileiros acerca da educação permanente, cabe dizer que a Teoria do Capital Humano (Schultz, 1973), teoria do desenvolvimento, constituiu-se, no Brasil, nesse momento, verdadeira "teoria da educação", gerando a crença de que o investimento em educação garantiria $\mathrm{o}$ aumento do desenvolvimento cognitivo e a competência técnica dos indivíduos. Como consequência, implantou-se o "otimismo

pedagógico" na sociedade, acreditando-se que o nível de escolaridade possibilitaria o aumento da capacidade de produção individual: a majoração da remuneração dos trabalhadores e a ascensão social e profissional. Desta forma, entende-se a predominância da visão Ieconomicista dada à educação permanente, como se verá a seguir. Educação Permanente: abordagens teóricas Foram muitos os educadores que se preocuparam em abordar o tema da educação permanente; cada qual de uma perspectiva, um enfoque, mas que, no seu conjunto, ofereceram muitas possibilidades de análise. Assim, serão apresentadas algumas abordagens dos mais destacados estudiosos da educação permanente e suas contribuições ao longo do tempo. Pierre Furter (1966) sugere o termo educação permanente para responder ao fato de que "o homem é um ser inacabado, que tende à perfeição e, por isso, se educa"; em consequência, a educação torna-se um processo contínuo que só termina com a morte. Para Furter, a prática dessa educação contínua deve ser objeto de reflexão, pois traz, em qualquer situação, o germe da mudança. Desta forma, o aludido autor não vincula a educação aos aspectos econômicos; afirma, apenas, que as funções sociais da educação devem ser submetidas ao caráter contínuo da maturação humana. Dumerval Trigueiro (1969) parte de uma abordagem política basicamente democrático-liberal, apresentando a educação permanente como alternativa para a extensão da escolaridade, e analisando-a em conexão com o problema da construção de uma nação moderna. Para o 
autor, a nação moderna é aquela em que a educação se democratiza, tornando mais fácil o dinamismo de sua evolução. Na sua concepção, a educação permanente é um "atalho" que permite chegar mais rápido ao futuro e alcançar o status de nação moderna - "sociedade industrializada, democrática, onde a ascensão das massas se processa sem se achatar as elites"; esse tipo de educação buscará a eficiência, vendo na educação o motor das transformações sociais.

Numa visão apenas pedagógica, Schwartz (1969) produz sua reflexão acerca da educação permanente em seus aspectos didáticos e metodológicos. Sua ótica privilegia a maneira de enfocar a educação de adultos, oscilando entre a reciclagem universitária e a chamada educação cultural. Contudo, sua análise dá-se apenas em função da transformação dos métodos e dos conteúdos de educação dos adultos.

Em seu texto sobre o tema, Arlindo Lopes Correia (1973) reflete sobre a educação permanente à luz da economia da educação, partindo de seus postulados básicos: vê a educação como fator de crescimento econômico (Schultz, 1973), devendo o Estado atender às exigências da força de trabalho qualificado, propondo programas e reformas educacionais. Defende a educação permanente em função "da melhoria da qualidade de vida da população", criando suas propostas a partir da reprodução de argumentos dos intelectuais das sociedades desenvolvidas, que pouco têm a ver com a realidade encontrada no Brasil. Em síntese, o fundamento de sua proposição é a reciclagem.

Correia propõe, ainda, uma solução para o Estado enfrentar o problema da falta de verbas educacionais. Apontando o modelo norteamericano de transferência da formação profissional às empresas e às associações privadas, em função de seus interesses imediatos, afirma que a proposta deixa de onerar os gastos do Estado, em relação a esse tipo de educação profissionalizante, ficando ao seu encargo apenas a educação geral. (Esta sugestão já está sendo aplicada no País, atualmente, permitindo ao governo enfrentar a "falta de recursos", abdicando daqueles que estão diretamente ligados ao capital privado na formação de recursos humanos para o crescimento da economia). 
Vanilda Paiva (1977a), estudiosa do assunto, conduz a discussão sobre Educação Permanente tendo em vista as relações entre a produção e a qualificação; o que caracteriza o modo de produção capitalista em sua fase tardia, constituindo o cerne de reflexões a educação global e a educação permanente. Paiva diz que a automação trouxe graves consequências para o trabalho humano e para a sua qualificação, uma vez que "o trabalho vivo" é substituído por trabalho mecânico em função da elevada produtividade das máquinas (Tecnologia). Consequentemente, a força de trabalho foi deslocada da produção direta, para incidir sobre as tarefas de direção e vigilância, constatando, em virtude disto, a modificação do "aspecto da qualificação da força de trabalho necessária à produção", em que a reciclagem periódica se torna necessária em função do fenômeno.

A autora comenta o surgimento e o desdobramento da ideia de educação permanente, afirmando ser a reciclagem o ponto de partida para se pensar esse tipo de educação. Para Paiva, outros problemas educacionais deveriam ser pensados, a partir de outras características do capitalismo tardio, como o tempo livre e a extensão da escolaridade.

Paiva foi além, mostrando que o sistema educacional não é capaz de suprir o mercado com a força de trabalho adequada às atividades industriais do momento em questão. Para ela, segundo o modelo de desenvolvimento brasileiro, esta constatação deu origem, por um lado, "à consideração da reciclagem como uma anomalia" a ser corrigida por uma reforma de ensino plena e, por outro, à certeza de que toda educação não poderia ser realizada pelo sistema educacional tradicional, determinando que se pense a educação dentro de uma proposta mais ampla, ou seja, da educação permanente.

Sintetizando sua posição, Paiva afirma serem muitos os motivos pelos quais são mais vantajosos e mais fáceis para as empresas proporcionarem a reciclagem do que esperar uma reforma educacional, para resolver seus problemas de treinamento da força de trabalho. A partir de sua síntese, propõe algumas soluções: "basta o Estado permitir que as firmas que treinam seus trabalhadores, para poder melhor utilizá-los, deduzam dos impostos a pagar 
os recursos que aplicaram na reciclagem". Completando, torna-se bastante elucidativo mencionar, devido aos objetivos desse trabalho, a conclusão da autora: "A reciclagem e a adaptação a novas formas de trabalho podem ser facilitadas pela disposição de "aprender a aprender", ou seja, por aquilo que classicamente é apresentado como o fundamento da educação permanente" (Paiva, 1977b).

Entre os estudiosos brasileiros da educação de adultos, Álvaro Vieira Pinto (1986) é um dos mais atuantes. Apesar de não debater o tema da educação permanente explicitamente, notam-se em seu trabalho abordagens que colocam a educação como tarefa permanente ao longo de toda a vida do indivíduo. Pinto expõe a importância da educação contínua de adultos, afirmando que "o que distingue uma modalidade de educação da outra, ou seja, a educação em crianças ou em adultos, não é o conteúdo, os métodos, mas sim os interesses que a sociedade como um todo tem, quando educa a criança ou o adulto". Assim, o autor afirma que a distinção de idades se traduz pelas diferentes experiências acumuladas.

O autor comenta, ainda, acerca do papel do educando adulto como "membro pensante e atuante em sua comunidade". Para ele, a realidade social do adulto pressupõe um conjunto de conhecimentos básicos, relacionados ao mundo do trabalho. Partindo da ideia de Sartre, de que o homem é produto do seu trabalho, o adulto percebe, na visão de Pinto, o seu trabalho incorporar-se ao trabalho social, com a finalidade de construir a sociedade, como próprio executor, sendo influenciado por condicionamentos sociais como salários, valores, instituições, ideologias, etc. Por isso, o autor diz que "o adulto é, por conseguinte, um trabalhador-trabalho", pois, se por um lado, só sobrevive se efetuar trabalho, por outro, só pode fazê-lo dependendo das condições oferecidas pela sociedade em que se encontra.

Em última análise, Pinto apresenta a educação sempre como processo contínuo e permanente, onde o homem tende a dar prosseguimento à obra educacional: 
Em virtude do caráter criador do saber, que todo saber possui, o homem que adquire conhecimentos é levado naturalmente a desejar ir mais além daquilo que lhe é ensinado.

Moacir Gadotti (1979) define a educação permanente como uma necessidade de continuar constantemente a formação, distinguindo-a do aparecimento dessa necessidade numa determinada época, provocada por uma sociedade que exige constante renovação dos conhecimentos.

Afirmando ser a educação "um combate em favor de uma sociedade mais justa, por mais igualdade, por menos seletividade, por um homem mais humano", indaga acerca da educação permanente: "Para quem?", "Contra quem age esta educação?" Em função destas questões, conclui que a educação permanente propõe um discurso ideológico, o qual mascara interesses ocultos, levando-o a constatar que a educação permanente é "como uma modalidade nova e aperfeiçoada de educação do colonizador". Segundo Gadotti, para os trabalhadores, a educação permanente é um aumento de formação profissional, promotora de falsas promessas, pois cria "a esperança e a crença em uma formação para a promoção individual", cujo objetivo único é a produtividade e o crescimento econômico capitalista. Desta forma, afirma:

...a educação permanente é, nesse sentido, profundamente conservadora e reacionária, na medida em que prolonga o mito de que a educação e a formação são pressupostos de toda ação, e que basta um "suplemento de educação" para mudar a ordem das coisas.

Finalizando, na opinião do autor, a educação permanente cria a ilusão de que a educação seja "a alavanca da transformação social".

\section{A educação permanente e a qualidade total}

É fato que ao longo dos últimos anos, cada vez mais, vem se abrindo o mercado brasileiro aos produtos e aos serviços estrangeiros. A competitividade torna-se palavra de ordem, para que a produção nacional possa sobreviver. Em consequência, o empresariado brasileiro 
vislumbra o investimento em qualidade como a grande saída para os problemas vivenciados pelas empresas. Essa proposição, baseada no modelo desenvolvimentista neoliberal japonês, parte do pressuposto de que produzir com melhor qualidade implica produzir com maior produtividade, "resultando em menor desperdício, menos retrabalho, levando a custos menores" (Machado, 1993).

Segundo Souza Júnior (1994), "a visão de mundo que envolve a ideologia da qualidade é racionalista, de tipo instrumental", posto que objetiva o condicionamento do pensar, a personalidade e a criatividade dos indivíduos ou de uma coletividade, formando um comportamento eficiente e eficaz ao mundo do capital. Nesse sentido, a mídia e as formas de informação tornam-se vitais ao mundo da qualidade.

Sob o ponto de vista marxista (Machado, 1993), há uma dimensão ideológica no controle da qualidade total, gerando alguns objetivos a serem alcançados através dos novos métodos de gerenciamento das empresas. Segundo o autor, existem quatro objetivos essenciais:

1. favorecer a identificação do trabalhador com a sua atividade de trabalho e com a organização empresarial;

2. preparar a organização para as mudanças tecnológicas e organizacionais mais exigidas pelo regime da produção integrada e flexível;

3. submeter toda a organização aos novos critérios internacionais de competitividade c produtividade;

4. legitimar o mecanismo do mercado como referenciador das políticas das instituições.

As atuais transformações no processo de acumulação capitalista introduzem mudanças qualitativas que, naturalmente, atingem os métodos de produção. A microeletrônica aparece como um dos baluartes fundamentais, gerando as mais radicais transformações (Fidalgo, 1944).

A cibernética e a informática constituem elementos de controle social, em que tudo precisa adaptar-se à realidade tecnológica da informatização, sendo uma de suas características mais expressivas a capacidade de realizar tarefas de forma extremamente rápida, antes realizadas pela mão humana: o homem perde lugar para a máquina, restando-lhe atividades de controle e supervisão. 
Traduzindo, sinteticamente, o novo modelo, Souza Júnior (1994) comenta:

O novo modelo é flexível. A tecnologia de base microeletrônica possibilita a flexibilidade na implantação dos novos sistemas e estruturas de organização do trabalho. São flexíveis os equipamentos e também o processo de trabalho. O princípio da flexibilidade afeta a própria concepção de trabalho qualificado: este perde seu sentido técnico de habilidade requerida para o desempenho de uma função, relacionada geralmente à experiência acumulada, ganhando uma conotação mais propriamente comportamental, relacionada à versatilidade, à mudança nos hábitos pessoais e de trabalho que procuram conformar e ajustar a força de trabalho às exigências de flexibilização.

Em decorrência, o novo trabalhador tem de ser também flexível e com alto grau de abstração. Para se estar apto ao novo modelo, é preciso dominar diversos códigos linguísticos, manusear e saber utilizar o computador, estar preocupado com a qualidade e os custos e ser, sobretudo, multifuncional.

As novas exigências profissionais, contudo, obrigam a mudanças na formação do novo trabalhador, trazendo obviamente mudanças na educação. No atual contexto, às empresas interessa o trabalhador de conhecimento genérico, não especializado, de forma que possa assumir várias funções, ser polivalente. Desta forma, exige-se do sistema educacional e, principalmente, do ensino superior em particular, uma mudança radical, fundamentalmente no que se refere aos currículos, ao tipo de conhecimento que o futuro trabalhador deverá receber, reordenando-se o processo de ensino no intuito de tornar o trabalhador subjetivo, operacional e lucrativo, apto a ser funcional à lógica do sistema produtivo. Nessa perspectiva, facilmente se percebe o perfil da Escola para a "Qualidade Total", voltada à preparação da nova força de trabalho plurifuncional ou de um exército de desempregados.

Sob os pontos de vista epistemológico e pedagógico, o desafio de se alcançar a qualidade resume-se em "construir e participar"(Demo, 1994). Demo constata que a "qualidade total" virou moda no Brasil, considerada a proposta fundamental, desde que não permaneça "apenas 
em procedimentos organizativos e em táticas de aliciamento de funcionários e clientes, e respectivos treinamentos". Assim, segundo o autor, a "qualidade total" só é compatível com sistemas produtivos que se sustentam no conhecimento, de forma inovadora.

Do ponto de vista da formação do "trabalhador moderno", seu perfil deve estar pautado no aprender a aprender, saber pensar e não só saber fazer funcionar. Tendo em vista esse perfil, Demo (1994) propõe que a formação do trabalhador seja permanente:

Isso inclui condição de avaliar processos complexos, visão geral da situação e evolução, capacidade multidisciplinar e, sobretudo, formação permanente. Sendo qualidade, atributo humano, ela somente emerge, faz e se faz em ambiente humanamente adequado.

$\mathrm{Na}$ visão de Demo, se a "qualidade total" não ressaltar o compromisso com a qualificação humana, centralizando-se nos desafios da educação e do conhecimento, representará mera moda, "fabricando treinamento fantasiosos, além de aliciamentos indignos".

Em síntese: se do ponto de vista marxista, a "qualidade total" é uma nova pedagogia do capital para a cooptação dos trabalhadores, como forma de aliciamento do processo de acumulação capitalista, da perspectiva epistemológica, centrada no conhecimento e na educação, a "qualidade total" poderá levar à construção e à participação na sociedade, desde que se fundamente no compromisso, sobretudo com a qualificação humana, não só no plano material, mas, principalmente, nos planos moral e no ético.

\section{A educação permanente e o ensino superior brasileiro na era da qualidade total}

Na década de 60, momento em que era implementado o novo modelo econômico no Brasil, surgiram as discussões acerca das mudanças educacionais, a fim de satisfazer as necessidades do novo 
mercado que se criara. Nos anos 60 , a polémica sobre educação permanente constituía algo revolucionário no contexto educacional internacional e, consequentemente, deveria estar presente nas novas propostas de mudança para os sistemas educacionais, principalmente em países considerados em fase de desenvolvimento ou subdesenvolvidos.

O modelo econômico capitalista monopolista brasileiro propôs cada vez mais a formação profissional acelerada, como já se viu, e profissionais qualificados às novas funções oferecidas pelo mercado. Isso trouxe às reformas de ensino muitos valores apregoados pelos efervescentes estudos da Unesco sobre educação permanente. Sobre a afirmação, comenta Gadotti (1979):

...enquanto discurso, a educação permanente é um envelope vazio, no qual os educadores caprichosos e os tecnocratas da educação, ligados, notadamente, às organizações internacionais, incluem todos os seus desejos de reformas educacionais.

Em particular, a reforma do ensino superior foi atingida por tais discussões, trazendo no seu conjunto várias proposições relacionadas à produção e à qualificação (Paiva, 1977b).

A extensão é algo que a Lei $\mathrm{n}^{\circ} 5.540$ (1968) propõe, sendo indiscutivelmente a expressão da educação permanente no ensino superior. Sobre esse aspecto, Violeta Villas Boas (1982) comenta:

Por igual, cada vez mais se mostra imperativa a participação da Universidade nesse processo. Ela é chamada hoje a desempenhar um papel mais amplo do que o desempenhado até pouco tempo, assumindo, em proporção maior, sua função como agente de "extensão". Para isso deve oferecer, ao lado de seus cursos regulares, um espectro diversificado de iniciativas de atualização e desenvolvimento, à clientela das mais diferentes origens."

Os cursos de extensão, cujo valor é justamente reconhecido pela possibilidade conferida ao adulto de retomar estudos interrompidos ou estudos específicos e especializados, a qualquer tempo, e os cursos de curta duração em nível superior, com vistas a conduzir com maior 
objetividade e rapidez à formação de técnicos especializados, são algumas propostas claras da inserção de pressupostos da educação permanente na universidade brasileira, entendida como $3^{\circ}$ grau. Contudo, hoje, com os novos preceitos da "qualidade total", a universidade é chamada a rever tais posições, devido às novas contingências do momento econômico e tecnológico.

$\mathrm{Na}$ era da qualidade, a universidade assume papel decisivo na formação de profissionais de nível universitário (Brasil. Lei $\mathrm{n}^{\circ}$ 5.540, 1968), uma vez que o novo modelo da flexibilização exige a formação de indivíduos também flexíveis, aptos a ser polivalentes enquanto força de trabalho. Com isto, o ensino superior, de forma geral, deve evocar para si uma mudança radical na produção do conhecimento que ele propõe à sociedade, tendo em vista o novo perfil da força de trabalho que o mercado de trabalho exige atualmente.

Tais mudanças nesse grau de ensino devem se realizar em função das constantes transformações por que passa o mercado, tendo a universidade de estar instrumentalizada, através de mecanismos eficientes, de forma a não defasar o conhecimento que ela emana. Assim, o "aprender a aprender" necessita pautar a educação superior atual, com a finalidade de formar adequadamente a nova força de trabalho, à luz do momento tecnológico.

Quadro 1 - Novo perfil da força de trabalho
\begin{tabular}{|l|}
\hline Subjetividade (valorização individual) \\
\hline Racionalidade \\
\hline Criatividade \\
\hline Flexibilidade \\
\hline
\end{tabular}

\begin{tabular}{|l|}
\hline Polivalência \\
\hline Preocupação com custos \\
\hline Preocupação com a qualidade \\
\hline Domínio de vários códigos \\
\hline Adaptar-se e saber usar o computador \\
\hline Obter conhecimentos genéricos \\
\hline Formação para o saber pensar \\
\hline
\end{tabular}




\section{A avaliação da qualidade da universidade e o conhecimento}

A produção do conhecimento que a universidade propõe depende, sobretudo hoje, em tempos de "qualidade total", da população alvo a que se destina.

Na perspectiva da "qualidade total", qualidade é a possibilidade de se produzir com mais produtividade e de forma satisfatória às especificações e exigências dos clientes, ou seja, "tem qualidade aquele que consegue fornecer produtos e serviços sem falhas" (Fidalgo, 1994). Como apropriação ao uso, a qualidade está relacionada a uma visão individual e subjetiva do consumidor, o qual propõe a titulação de alta qualidade a um produto ou serviço: assim ambos terão qualidade, desde que estejam de acordo com as necessidades e anseios do consumidor (Souza Júnior, 1994).

Em relação à educação, o conceito de qualidade, conforme a lógica da "qualidade total", é aplicado como em outras áreas, ou seja, a qualidade é mensurada pela satisfação do "cliente" específico, alvo do processo ensino/aprendizagem, de acordo com suas expectativas e necessidades, apesar de o produto e/ou serviço propostos pela escola serem de difícil mensuração e se realizarem num âmbito simbólico (Bourdieu, 1974).

Transportando-se o conceito especificamente ao ensino superior brasileiro, com a finalidade de avaliar a "qualidade", surge a indagação: como estimar a qualidade de serviços prestados pelas instituições de ensino superior, públicas ou privadas, universidades ou escolas isoladas, se existem entre elas complexas diferenciações? Como revela Schwartzman (1988), a grande "mitificação" da universidade brasileira, entendida como escola de $3^{\circ}$ grau, reside no fato de supor que as diferenças não existem de instituição a instituição. Na realidade, o que se verifica é uma pluralidade de dimensões e um sistema de ensino superior "bastante complexo e diferenciado, em que grupos distintos buscam objetivos distintos, nem sempre comparáveis entre si". 
Em função do exposto, nota-se que não se pode avaliar a qualidade de todas as instituições de ensino superior pelo parâmetro ideal do modelo-padrão (Brasil. Lei $n^{\circ} 5.540,1968$ ). Para que haja o real julgamento de valor no aspecto qualitativo, deve-se estabelecer nitidamente o perfil do público alvo desses serviços, sendo suas necessidades e expectativas o ponto de partida para a avaliação da qualidade dos serviços prestados por cada instituição especificamente.

Seguindo esse raciocínio, as instituições particulares de ensino superior, bem como algumas instituições públicas - universidades ou estabelecimentos isolados -, não podem ser avaliadas sob o aspecto da qualidade de seus serviços, do ponto de vista das instituições consideradas de maior prestígio, verdadeiros "centros de excelência", que se notabilizam pela pesquisa científica. As primeiras, sendo vinculadas ao mundo empresarial, recebem público específico, predominantemente constituído por trabalhadores da classe média que, por falta de opções de emprego e de ascensão profissional e social, percebem na escola de $3^{\circ}$ grau uma chance, quem sabe a única, de romper o sistema de estratificação imposto na sociedade brasileira (Cunha, 1972).

Então, finalizando, cabe indagar: como um cidadão que trabalha oito horas diárias para sua subsistência e de sua família, estudando geralmente à noite, pode ser comparado, quanto aos seus anseios e necessidades, àquele que não necessita do trabalho simultâneo ao estudo como meio de sobrevivência, dispondo de tempo integral para estudar?

Tranquilamente, o aspecto da abordagem sobre qualidade no ensino superior poderá ser generalizado aos vários níveis educacionais. Apesar de, sob o aspecto legal, a escola se apresentar como única, igualitária e democrática, sabe-se que empiricamente isto não acontece. Em função disso, mensurar a qualidade na educação como um todo implicará, obrigatoriamente, a sondagem do perfil do aluno que cada escola recebe, segundo suas necessidades, expectativas e anseios, bem como se conhecer com bastante clareza a vocação individual e original de cada instituição de ensino. 


\section{Conclusão}

Os pressupostos da qualidade total sugerem a educação permanente como única forma de manter o trabalhador flexível e apto às várias e possíveis funções dentro da empresa. Sabendo-se que a especialização cede lugar à multifuncionalidade, percebe-se que a educação permanente, aplicada a serviço do capital ou da qualificação humana, é a única saída para o trabalhador no atual momento econômicotecnológico, posto que a competitividade e a microeletrônica exigem acelerada renovação dos conhecimentos e das aptidões que a nova força de trabalho necessita possuir, com a finalidade de se tornar polivalente.

Com efeito, o aprender a aprender deve fundamentar a educação em todos os níveis, de forma que a escola possa criar um novo tipo de indivíduo, apto a pensar, a ser subjetivo, e não apenas a fazer funcionar, de forma que sua criatividade permita "construir" possibilidades profissionais e melhor qualidade de vida, mediante a "participação" efetiva do seu saber pensar.

\section{Referências bibliográficas}

BORDIEU, Pierre. A economia das trocas simbólicas. São Paulo: Perspectiva, 1974.

BRASIL. Lei n5.540 de 28 de novembro de 1968. Fixa normas de organização e funcionamento do ensino superior e sua articulação com a escola média, e dá outras providências. Diário Oficial [da República Federativa do Brasil], Brasília, 29 nov. 1968.

CORREIA, Arlindo Lopes. Educação permanente e educação de adultos no Brasil. Brasília: Mobral, 1973.

CUNHA, Luiz Antônio. Educação e desenvolvimento social no Brasil. Rio de Janeiro: F. Alves, 1972. 
DEMO, Pedro. Educação e qualidade. Campinas: Papirus, 1994.

FIDALGO, Fernando Selmar. Qualidade, novas tecnologias e educação. In: Controle da qualidade total: uma nova pedagogia do capital. Belo Horizonte: Movimento de Cultura Marxista, 1994.

FURTER, Pierre. Educação e vida. Petrópolis: Vozes, 1966.

GADOTTI, Moacir. Ação pedagógica e prática social transformadora. Educação \& Sociedade, São Paulo, v. 1, n.4, 1979.

MACHADO, Lucília R. S. Controle da qualidade total: uma nova gestão do trabalho, uma nova pedagogia do capital. Extra Classe em Revista, Minas Gerais, v.2, n.1, out. 1993.

PAIVA, Vanilda. Educação permanente: ideologia educativa ou necessidade econômico-social. Rio de Janeiro: Síntese, 1977a.

. Educação permanente e capitalismo tardio. Rio de Janeiro: Síntese, 1977b.

PINTO, Álvaro Vieira. Sete lições sobre educação de adultos. São Paulo: Cortez, 1986.

ROMANELLI, Otaíza de O. História da educação no Brasil. Petrópolis: Vozes, 1989.

SCHULTZ, Theodore W. O capital humano. Rio de Janeiro: Zahar, 1973.

SCHWARTZ, B. Reflexões sobre o desenvolvimento da educação permanente. Revista Brasileira de Estudos Pedagógicos, Rio de Janeiro, v.5, n.113, jan./mar. 1969. 
SCHWARTZMAN, Simon. Como a universidade brasileira está se pensando. Rio de Janeiro: IUPERJ, 1988.

SOUZA JÚNIOR., Hormindo. Forma e conteúdo na construção ideológica do discurso da qualidade. In: Controle da qualidade total: uma nova pedagogia do capital. Belo Horizonte: Movimento de Cultura Marxista, 1994.

TRIGUEIRO, Dumerval. Um novo mundo, uma nova educação. Revista Brasileira de Estudos Pedagógicos, Rio de Janeiro, v.5, n. 113, jan./ mar. 1969.

VILLAS BOAS, Violeta. Conceitos básicos em educação: análise e confronto. Rio de Janeiro: SENAC, 1982.

Recebido em 7 de junho de 1995.

Ana Shirley de França Moraes, doutoranda em Educação na Universidad de La Habana, Cuba, é professora titular da Universidade Estácio de Sá (Unesa).

This paper discusses the issue of permanent education based on the investigation Student-worker in the university: his representations and expectations concerning the labor market and teaching. It aims at providing ground to the search of school knowledge by the worker who, many times, sacrifices himself and hisfamily, but is determined to end up his course parallelly to his work. This paper flows through a theoretical retrospective on the subjet, focusing several studies of Brazilian scholars and their approach to the matter. Following that, the total quality will be analysed by means of a brief characterization showing its relationship with education from a marxist point ofview as well as from a pedagogical and epistemological approach, thus 
revealing the presence of the "learning to learn", a basic concept ofthe permanent education which lies implicitly in the total quality principies.

Varticle presente le thème de Veducation permanente, à partir de $V$ investigation faite pour la recherche Travailleur-étudiant dans l'enseignement supérieur: ses représentations et ses expectatives concernant le marche de travail et l'enseignement, avec le but defonder la recherche sur le savoir scolaire de la part du travailleur, qui beaucoup de fois se voit sacrifié et sa famille, mais se maintient determine à réaliser ses études, simultanément avec son travail. On développera cet article à travers une rétrospective théorique sur le thème, analysantplusieurs études d'intellectuels brésiliens. En suite, on abordera la qualité totale, à travers une breve caractérisation, en montrant sa relation avec Veducation du point de vue marxiste, de même que la perspective pédagogique et epistémologique et, ainsi, se révélera la presence "d'apprendre à apprendre", príncipe basique de la qualité totale.

El artículo presenta el tema educación permanente, a partir de la investigación realizada para la pesquisa Trabajador-estudiante en la ensenanza superior: sus representaciones y expectativas en relación ai mercado de trabajo y a la ensenanza, con elfin de fundamentar la búsqueda a través dei conocimiento dei trabajador, que a veces se ve sacrificado y la sua família, pêro se mantiene determinado a estudiar, concomitantemente ai trabajo. Este artículo se desarrollará haciendo una retrospectiva teórica sobre el tema y el análisis de los vários estúdios de los intelectuales brasilehos y sus enfoques. En seguimiento, se hablará sobre la cualidade total, a través de breve 
caracterización, mostrando su relación con la educación, bajo el punto de vista marxista, y también las perspectivas pedagógica y epistemológica, y así se revelará la presencia dei "aprender a aprender", fundamento básico de la educación permanente, que se presenta implícito en los presupuestos de cualidad total. 